\title{
Gelombang Auditory Brainstem Response (ABR) pada Anak di Bawah Lima Tahun
}

\author{
Wijana, Alex Syamsuddin, Yussy Afriani Dewi \\ Departemen THT-KL Fakultas Kedokteran Universitas Padjadjaran \\ Rumah Sakit Dr. Hasan Sadikin Bandung
}

\begin{abstract}
Abstrak
Auditory brainstem response (ABR) adalah pemeriksaan pendengaran yang reliabel, bertujuan untuk menilai singkronisasi saraf pendengaran perifer. Masalah pendengaran pada saat balita akan memberikan efek pada perkembangan, khususnya bicara dan bahasa. Deteksi dini merupakan hal yang penting sementara referensi nilai ABR untuk Indonesia saat ini masih belum ada. Penelitian ini bertujuan untuk mengetahui nilai ABR pada anak usia di bawah 5 tahun dengan pendengaran normal. Telah dilakukan penelitian deskriptif potong lintang pada 198 balita, terdiri atas 119 laki-laki dan 79 perempuan berusia antara 3 bulan hingga 5 tahun di Poliklinik Dengar dan Bicara Rumah Sakit Dr. Hasan Sadikin Bandung, pada bulan Desember 2008 hingga Juni 2011, pada semua subjek dilakukan pemeriksaan ABR kemudian dihitung rerata setiap gelombang. Balita perempuan memiliki masa laten absolut gelombang I, III dan V, serta masa laten antara gelombang I-III, III-V, dan I-V lebih pendek secara bermakna dibandingkan dengan balita laki-laki. Masa laten rata-rata gelombang $\mathrm{V}$ pada balita laki-laki 6,07 msec $\pm 0,39 \mathrm{dan}$ perempuan 5,90 msec $\pm 0,34$. Kelompok usia $0-1$ tahun memiliki masa laten absolut yang paling panjang. Tidak terdapat perbedaan masa laten absolut dan antara gelombang di kedua telinga pada laki-laki maupun perempuan pada usia di bawah lima tahun. Simpulan, masa laten absolut rata-rata gelombang V pada anak perempuan usia di bawah

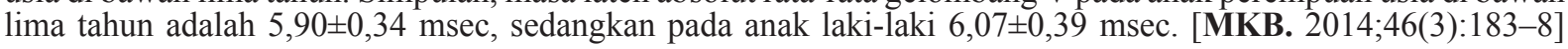

Kata kunci: Gelombang ABR, masa laten ablosut, masa laten antar gelombang

\section{Auditory Brainstem Response (ABR) Waveforms in the First Five Years}

\begin{abstract}
Auditory brainstem response (ABR) is a reliable hearing examination. It reflects the integrity of synchronous neurons firing within the periphery auditory pathways. Hearing impairment on the first five years will cause speech and language delays; therefore, early detection of hearing loss is very important. Nowadays, there is still no ABR value reference in Indonesia. The aim of this study was to establish the ABR values in toddlers with normal hearing. This was a descriptive cross-sectional study on 198 subjects between the ages of 3 month and 5 years in the period of December 2008 to June 2011 at the Hearing and Speech Clinic, Dr. Hasan Sadikin General Hospital, Bandung. The hearing level were diagnosed by ABR examination in all subjects and the mean of ABR wave was calculated. Girls displayed shorter absolute latency of wave I, III and V, and interwave latency of I-II, III-V, and I-V compared to boys. The wave V latency in boys was $6.07 \mathrm{msec} \pm 0.39$ and $5.90 \mathrm{msec} \pm 0.34$ in girls. The $0-1$ years old group have the longest absolute and interwave latencies. There was no significant differences in absolute and interwave latency between both ears in boys and girls. The conclusion of this study is the average wave V latencies in boys and girls are $6.07 \pm 0.39 \mathrm{msec}$ and $5.90 \pm 0.34$, respectively. [MKB. 2014;46(3):183-8]
\end{abstract}

Key words: ABR wave, absolute latency, interwave latency.

Korespondensi: Wijana, dr., Sp.THT-KL(K), Departemen THT-KL Fakultas Kedokteran Universitas Padjadjaran/Rumah Sakit Dr. Hasan Sadikin Bandung, Jalan Pasteur No. 38 Bandung, mobile 08122017734, e-mail wijana_tbl@yahoo.com 


\section{Pendahuluan}

Lima tahun pertama kehidupan seorang anak merupakan suatu masa yang menentukan untuk kehidupan anak selanjutnya. Tiga tahun pertama kehidupan anak adalah masa perkembangan dan pematangan otak, saat ini juga merupakan periode perkembangan bicara dan bahasa yang intensif. Jika pada masa tersebut terjadi kerusakan pada salah satu organ sensori, maka keadaan tersebut akan memberikan efek terhadap perkembangan seorang anak, seperti gangguan dengar yang memberikan efek pada perkembangan bicara dan bahasa. Kondisi tersebut pada perkembangan selanjutnya dapat memengaruhi perilaku, sosial dan akademik penderitanya, oleh karena itu deteksi dini gangguan dengar merupakan keadaan yang perlu dilakukan, sehingga dapat diberikan intervensi sedini-dininya supaya anak tersebut dapat terhindar dari keterlambatan bicara. Hal ini tampak dari hasil penelitian Yoshinaga-Itano ${ }^{1}$ yang menyatakan bahwa anak yang dideteksi kemudian dilakukan intervensi pada usia $<6$ bulan menunjukkan nilai berbicara dan bahasa yang lebih baik daripada anak yang diintervensi setelah usia 6 bulan.

Gangguan berbicara dan bahasa anak dialami oleh 5-8\% usia prasekolah serta $17 \%$ usia 5 tahun, ${ }^{2}$ dan sekitar $75 \%$ anak tersebut menderita gangguan dengar. ${ }^{3}$ Data Departemen Rehabilitasi Medik RSCM tahun 2006, menunjukan 10,13\% pasien anak didiagnosis memiliki keterlambatan bicara dan bahasa. Gangguan pendengaran pada bayi dan anak sering kali tidak disadari oleh orangtua dan lingkungan serta penderita, karena secara fisik anak tumbuh normal, berbeda dengan anak yang memiliki gangguan penglihatan dan gangguan perkembangan.

Deteksi gangguan pendengaran pada seorang anak dapat dilaksanakan dengan pemeriksaan subjektif maupun objektif. Auditory brainstem response atau ABR merupakan pemeriksaan pendengaran yang bersifat objektif dan dapat dipercaya. Pemeriksaan ini merupakan rekaman secara elektrofisiologis respons yang berasal dari aktivasi jaras pendengaran terhadap stimulus suara, mulai dari koklea sampai sepanjang batang otak, menunjukkan integritas singkronisasi saraf. Pemeriksaan ini noninvasif dan mempunyai nilai objektif yang cukup tinggi. Karena sifat tersebut, maka ABR sering digunakan di klinik. ${ }^{4}$ Melalui elektroda di permukaan kulit kepala atau telinga yang cukup jauh dari sumber generator neural, tes ABR dapat merekam perubahan potensial listrik di sepanjang jalur pendengarn perifer yang timbul setelah pemberian rangsang suara. Hasil rekaman tersebut melalui proses amplifikasi komputer dapat menghasilkan suatu seri gelombang yang menggambarkan aktivitas saraf auditorius dan area sepanjang jalur pendengaan mulai dari koklea sampai sepanjang saraf auditorius di batang otak. ${ }^{5}$

Auditory brainstem response (ABR) adalah bentuk gelombang yang memperlihatkan fungsi elektrofisiologik sebagai suatu respons terhadap stimulus suara yang terjadi dalam waktu 10 detik setelah pemberian stimulus..$^{5}$ Jewett dan Williston membagi gelombang yang terjadi dalam 10 detik tersebut menjadi 7 (tujuh) gelombang dengan memberi angka Romawi untuk masing-masing puncak gelombang tersebut. Setiap gelombang menunjukkan integritas saraf di area tertentu di sepanjang jaras pendengaran; gelombang I menunjukkan aktivitas dari bagian distal N.VIII, gelombang II menunjukkan aktivitas dari bagian proksimal N. VIII, gelombang III menunjukkan aktivitas setinggi nukleus koklearis, gelombang IV memperlihatkan aktivitas dari kompleks olivari superior, serta kemungkinan juga ada kontribusi dari nukleus koklearis dan lemniskus lateral, gelombang $\mathrm{V}$ memperlihatkan aktivitas dari lemniskus lateral dan kolikulus inferior, gelombang VI dan VII didominasi oleh aktivitas dari kolikulus inferior. ${ }^{6}$ Gelombang IV dan V kadang bergabung membentuk kompleks IV-V. Komponen amplitude bervariasi antara setiap subjek, namun puncak masa laten gelombang I, III, dan $\mathrm{V}$ relatif tetap pada semua subjek. Gelombang $\mathrm{V}$ adalah gelombang yang paling stabil, mudah untuk dinilai bahkan sampai pada stimulus suara intensitas rendah dan bermakna secara klinis, ${ }^{6}$ oleh karena itu penilaian potensial ABR predominan berdasarkan pada masa laten (interval waktu antara onset stimulus dan puncak gelombang) puncak absolut. ${ }^{5}$

Penilaian gelombang ABR tersebut terdiri atas identifikasi gelombang I sampai V, masa laten absolut, masa laten antara gelombang, perbedaan masa laten antara kedua telinga, rasio amplitudo gelombang $\mathrm{V}$ dan $\mathrm{I}$, dan fungsi intensitas stimulus terhadap masa laten. ${ }^{5}$

Terdapat perbedaan yang berhubungan dengan perkembangan terhadap morfologi gelombang, amplitude, dan masa laten gelombang ABR. Pada awal kehidupan, hanya gelombang I, III, dan V yang muncul dengan masa laten yang panjang, amplitudo gelombang I lebih besar daripada gelombang $\mathrm{V}$, dengan berjalannya waktu, terjadi perubahan, berupa semakin jelasnya gelombang V dibandingkan dengan gelombang lainnya. ${ }^{6}$

Saat ini literatur di Asia khususnya Indonesia yang memberikan informasi gambaran gelombang ABR terutama pada anak di bawah lima tahun (balita) untuk populasi wilayah ini masih sangat sedikit. Acuan yang digunakan untuk penilaian morfologi gelombang ABR masih bersumber 
dari negara barat yang memiliki ras berbeda dari populasi di Asia, dengan demikian perlu acuan untuk populasi di Asia, khususnya anak balita.

Berdasarkan uraian di atas, maka dilakukan penelitian yang memilki tujuan untuk melihat bagaimana morfologi gelombang ABR pada anak balita di poliklinik Dengar dan Bicara Rumah Sakit Dr. Hasan Sadikin Bandung. Penelitian ini diharapkan dapat menambah khazanah acuan untuk nilai-nilai parameter gelombang ABR pada anak.

\section{Metode}

Penelitian ini bersifat deskriptif melalui metode potong lintang. Data diambil dari data sekunder berupa rekam medik pasien bayi dan anak di poliklinik THT-KL Rumah Sakit (RS) Dr. Hasan Sadikin Bandung, selama periode Desember 2008 hingga Juni 2011. Masa laten absolut dan antara gelombang ditentukan pada pemberian stimulus intensitas $60 \mathrm{dBHL}$.

Subjek penelitian ini adalah bayi dan anak yang telah dilakukan pemeriksaan ABR berdasarkan data rekam medik poliklinik Dengar dan Bicara RS Dr. Hasan Sadikin periode Desember 2008 hingga Juni 2011 dengan pendengaran normal berdasarkan data hasil pemeriksaan BERA. Usia pasien antara 0 hingga 5 tahun yang mencakup anak laki-laki dan perempuan.

Subjek yang diikutsertakan dalam penelitian ini berusia 0 sampai 5 tahun. Didapatkan hasil pemeriksaan timpanometri tipe A pada kedua telinga, otoacoustic emissions (OAE) yang pass pada kedua telinga, dan pemeriksaan pendengaran behavior observational audiometry (BOA) yang normal (berespons pada stimulus $\leq 20$ decibel hearing level (dBHL)) serta terdapat gelombang $\mathrm{V}$ pada stimulus klik $20 \mathrm{dBnHL}$. Ambang dengar dikatakan normal bila terdapatnya gelombang $\mathrm{V}$ dengan stimulus klik pada intensitas 20 dBHL. Subjek tidak diikutsertakan pada penelitian bila memiliki riwayat tumor dan kelainan pada kepala leher, serta menderita penyakit sistemik, seperti hiperbilirubinemia, gangguan pada sistem imun, uremia, kelainan genetik, dan sindromal.

Alat pemeriksaan yang dipergunakan untuk menentukan ambang dengar adalah ABR tipe

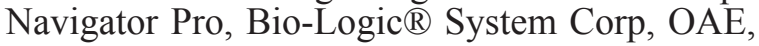

Tabel 1 Masa Laten Absolut (Milisekon) Gelombang ABR pada Balita Laki-Laki dan Perempuan

\begin{tabular}{|c|c|c|c|c|c|c|}
\hline \multirow[b]{2}{*}{ Usia (tahun) } & \multicolumn{3}{|c|}{ Laki-laki } & \multicolumn{3}{|c|}{ Perempuan } \\
\hline & $\begin{array}{l}\text { Rata-rata } \\
\text { AS }( \pm \text { SD })\end{array}$ & $\begin{array}{l}\text { Rata-rata } \\
\text { AD }( \pm \text { SD })\end{array}$ & $p^{*}$ & $\begin{array}{l}\text { Rata-rata } \\
\text { AS }( \pm \text { SD) }\end{array}$ & $\begin{array}{l}\text { Rata-rata } \\
\text { AD ( } \pm \text { SD) }\end{array}$ & $\mathrm{p}^{*}$ \\
\hline \multicolumn{7}{|l|}{ Gelombang I } \\
\hline $0-1$ & $2,1( \pm 0,32)$ & $2,09( \pm 0,27)$ & 0,9054 & $2,03( \pm 0,26)$ & $1,97( \pm 0,27)$ & 0,5017 \\
\hline$>1-2$ & $1,94( \pm 0,15)$ & $1,92( \pm 0,18)$ & 0,6653 & $1,90( \pm 0,10)$ & $1,90( \pm 0,10)$ & 0,5639 \\
\hline$>2-3$ & $1,92( \pm 0,12)$ & $1,94( \pm 0,15)$ & 0,5230 & $1,92( \pm 0,31)$ & $2,01( \pm 0,31)$ & 0,3098 \\
\hline$>3-4$ & $1,96( \pm 0,12)$ & $1,90( \pm 0,23)$ & 0,2734 & $1,92( \pm 0,12)$ & $1,95( \pm 0,19)$ & 0,6346 \\
\hline$>4-5$ & $1,93( \pm 0,12)$ & $1,95( \pm 0,13)$ & 0,8282 & $1,90( \pm 0,08)$ & $1,99( \pm 0,29)$ & 0,4805 \\
\hline \multicolumn{7}{|l|}{ Gelombang III } \\
\hline $0-1$ & $4,38( \pm 0,39)$ & $4,36( \pm 0,19)$ & 0,8187 & $4,21( \pm 0,57)$ & $4,14( \pm 0,59)$ & 0,7196 \\
\hline$>1-2$ & $4,10( \pm 0,22)$ & $4,17( \pm 0,35)$ & 0,3920 & $4,00( \pm 0,13)$ & $4,00( \pm 0,15)$ & 0,3699 \\
\hline$>2-3$ & $4,15( \pm 0,22)$ & $4,13( \pm 0,23)$ & 0,7057 & $4,05( \pm 0,27)$ & $4,08( \pm 0,43)$ & 0,7689 \\
\hline$>3-4$ & $4,11( \pm 0,22)$ & $4,23( \pm 0,23)$ & 0,1539 & $3,99( \pm 0,27)$ & $4,05( \pm 0,28)$ & 0,5832 \\
\hline$>4-5$ & $4,15( \pm 0,21)$ & $4,09( \pm 0,12)$ & 0,5240 & $1,90( \pm 0,08)$ & $1,99( \pm 0,29)$ & 0,7603 \\
\hline \multicolumn{7}{|l|}{ Gelombang V } \\
\hline $0-1$ & $6,12( \pm 1,25)$ & $6,36( \pm 0,32)$ & 0,3570 & $6,08( \pm 0,39)$ & $6,13( \pm 0,32)$ & 0,7065 \\
\hline$>1-2$ & $6,01( \pm 0,42)$ & $6,14( \pm 0,52)$ & 0,3261 & $5,88( \pm 0,16)$ & $5,94( \pm 0,52)$ & 0,3699 \\
\hline$>2-3$ & $5,92( \pm 0,23)$ & $5,98( \pm 0,22)$ & 0,2489 & $5,79( \pm 0,39)$ & $5,93( \pm 0,22)$ & 0,2136 \\
\hline$>3-4$ & $5,91( \pm 0,26)$ & $6,05( \pm 0,58)$ & 0,2966 & $5,69( \pm 0,26)$ & $5,78( \pm 0,58)$ & 0,3952 \\
\hline$>4-5$ & $5,87( \pm 0,24)$ & $5,97( \pm 0,20)$ & 0,4136 & $5,81( \pm 0,12)$ & $5,85( \pm 0,20)$ & 0,6721 \\
\hline
\end{tabular}

Keterangan: $\mathrm{AS}=$ auris sinistra (telinga kiri); $\mathrm{AD}=$ auris dekstra (telinga kanan); $\mathrm{SD}=$ standar deviasi; * $=\mathrm{Uji}-\mathrm{t}$ 
Wijana: Gelombang Auditory Brainstem Response (ABR) pada Anak di Bawah Lima Tahun

Table 2 Masa Laten antara Gelombang BERA (milisekon) pada Balita Laki-laki dan Perempuan

\begin{tabular}{|c|c|c|c|c|c|c|}
\hline \multirow{2}{*}{$\begin{array}{c}\text { Usia } \\
\text { (tahun) }\end{array}$} & \multicolumn{3}{|c|}{ Laki-laki } & \multicolumn{3}{|c|}{ Perempuan } \\
\hline & $\begin{array}{l}\text { Rata-rata } \\
\text { AS }( \pm \text { SD })\end{array}$ & $\begin{array}{l}\text { Rata-rata } \\
\text { AD }( \pm \text { SD })\end{array}$ & $\mathbf{p}^{*}$ & $\begin{array}{l}\text { Rata-rata } \\
\text { AS }( \pm \text { SD })\end{array}$ & $\begin{array}{l}\text { Rata-rata } \\
\text { AD }( \pm \text { SD })\end{array}$ & $\mathbf{p}^{*}$ \\
\hline \multicolumn{7}{|c|}{ Gelombang I-III } \\
\hline $0-1$ & $2,34( \pm 0,43)$ & $2,30( \pm 0,28)$ & 0,6984 & $2,25( \pm 0,32)$ & $2,27( \pm 0,26)$ & 0,8382 \\
\hline$>1-2$ & $2,16( \pm 0,27)$ & $2,27( \pm 0,27)$ & 0,1481 & $2,08( \pm 0,14)$ & $2,11( \pm 0,18)$ & 0,5913 \\
\hline$>2-3$ & $2,22( \pm 0,24)$ & $2,19( \pm 0,19)$ & 0,5476 & $2,13( \pm 0,25)$ & $2,11( \pm 0,28)$ & 0,7911 \\
\hline$>3-4$ & $2,16( \pm 0,20)$ & $2,30( \pm 0,54)$ & 0,2499 & $2,07( \pm 0,21)$ & $2,11( \pm 0,28)$ & 0,6840 \\
\hline$>4-5$ & $2,12( \pm 0,31)$ & $2,14( \pm 0,19)$ & 0,8867 & $2,14( \pm 0,16)$ & $2,18( \pm 0,42)$ & 0,9318 \\
\hline \multicolumn{7}{|c|}{ Gelombang III-V } \\
\hline $0-1$ & $1,97( \pm 0,44)$ & $2,03( \pm 0,3)$ & 0.5758 & $1,80( \pm 0,25)$ & $1,86( \pm 0,26)$ & 0.4852 \\
\hline$>1-2$ & $1,91( \pm 0,32)$ & $1,97( \pm 0,30)$ & 0.4887 & $1,89( \pm 0,13)$ & $1,94( \pm 0,18)$ & 0.3601 \\
\hline$>2-3$ & $1,78( \pm 0,21)$ & $1,85( \pm 0,17)$ & 0.1145 & $1,78( \pm 0,13)$ & $1,80( \pm 0,18)$ & 0.6545 \\
\hline$>3-4$ & $1,79( \pm 0,20)$ & $1,84( \pm 0,17)$ & 0.4792 & $1,70( \pm 0,11)$ & $1,72( \pm 0,16)$ & 0.7136 \\
\hline$>4-5$ & $1,83( \pm 0,22)$ & $1,88( \pm 0,09)$ & 0.5881 & $1,78( \pm 0,17)$ & $1,79( \pm 0,17)$ & 0.9209 \\
\hline \multicolumn{7}{|c|}{ Gelombang I-V } \\
\hline $0-1$ & $4,30( \pm 0,45)$ & $4,27( \pm 0,34)$ & 0.7914 & $4,05( \pm 0,44)$ & $4,13( \pm 0,27)$ & 0.5243 \\
\hline$>1-2$ & $4,07( \pm 0,42)$ & $4,21( \pm 0,40)$ & 0.2242 & $3,93( \pm 0,17)$ & $4,03( \pm 0,27)$ & 0.2055 \\
\hline$>2-3$ & $4( \pm 0,21)$ & $4,04( \pm 0,19)$ & 0.3867 & $3,91( \pm 0,31)$ & $3,92( \pm 0,35)$ & 0.9153 \\
\hline$>3-4$ & $3,95( \pm 0,20)$ & $4,12( \pm 0,45)$ & 0.1049 & $3,77( \pm 0,21)$ & $3,83( \pm 0,29)$ & 0.5514 \\
\hline$>4-5$ & $3,95( \pm 0,34)$ & $4,01( \pm 0,26)$ & 0.7832 & $3,92( \pm 0,09)$ & $3,86( \pm 0,35)$ & 0.6928 \\
\hline
\end{tabular}

Keterangan: $\mathrm{AS}=$ auris sinistra (telinga kiri); $\mathrm{AD}=$ auris dekstra (telinga kanan); $\mathrm{SD}=$ standar deviasi; $*=\mathrm{Uji}-\mathrm{t}$

Diagnostic Audiometer tipe AD226 Interacoustic, serta timpanometri tipe AZ26 Interacoustic.

\section{Hasil}

Selama periode Desember 2008 hingga Juni 2011 terdapat sebanyak 702 (425 laki-Iaki dan 277 perempuan) pasien bayi dan anak yang telah dilakukan pemeriksaan auditory brainstem response (ABR) di Poliklinik Dengar dan Bicara Rumah Sakit Dr. Hasan Sadikin Bandung dengan 198 data yang sesuai dengan kriteria penelitian. Pada pemeriksaan dengan stimulus klik 60 dBHL tampak gelombang ABR khususnya gelombang I, Ill, dan V jelas teridentifikasi.

Subjek perempuan $(\mathrm{n}=79)$ mempunyai masa laten absolut gelombang I, III, dan V yang lebih

TabeL 3 Masa Laten Absolut Rata-rata dan antara Gelombang (milisekon) pada Balita Laki-laki dan Perempuan

\begin{tabular}{lccc}
\hline \multicolumn{1}{c}{ Masa Laten } & Laki-laki $( \pm$ SD) & Perempuan $( \pm$ SD) & p \\
\hline Gelombang I & $1,97( \pm 0,21)$ & $1,95( \pm 0,24)$ & 0,3815 \\
Gelombang III & $4,19( \pm 0,37)$ & $4,07( \pm 0,37)$ & $0,0017^{*}$ \\
Gelombang V & $6,07( \pm 0,39)$ & $5,90( \pm 0,34)$ & $0,0000^{*}$ \\
Masa laten antara gelombang & & & \\
I- III & $2,23( \pm 0,31)$ & $2,14( \pm 0,26)$ & $0,0022^{*}$ \\
III-V & $1,88( \pm 0,28)$ & $1,81( \pm 0,23)$ & $0,0061^{*}$ \\
I-V & $4,1( \pm 0,35)$ & $3,95( \pm 0,31)$ & $0,0000^{*}$ \\
\hline
\end{tabular}

Keterangan: * berbeda bermakna (uji-t); $\mathrm{SD}=$ standar deviasi 
pendek bila dibandingkan dengan subjek lakilaki ( $\mathrm{n}=119)$. Masa laten absolut I, III, dan V pada kedua telinga tidak berbeda, baik pada subjek laki-laki maupun perempuan. Masa laten absolut pada kelompok usia 0-1 tahun lebih panjang dibandingkan dengan kelompok usia di atasnya, dan relatif menetap setelah usia 2-3 tahun (Tabel 1).

Masa laten antara gelombang I-III, III-V, dan I-V tidak berbeda secara bermakna pada kedua telinga, baik pada subjek laki-laki maupun perempuan (Tabel 2). Kelompok usia 0-1 tahun memiliki masa laten antara gelombang yang lebih panjang dibandingkan dengan kelompok usia di atasnya, dan nilai masa laten antara gelombang relatif menetap setelah usia 2-3 tahun (Tabel 2).

Tidak terdapat perbedaan masa laten ratarata gelombang I antara subjek laki-laki dan perempuan $(\mathrm{p}=0,3815$; IK 95\%), namun terdapat perbedaan yang bermakna masa laten rata-rata gelombang III dan V ( $\mathrm{p}=0,0017$ dan $\mathrm{p}=0,0000$, IK 95\%), begitu juga masa laten rata-rata antara gelombang I-III, III-V, dan I-V ( $\mathrm{p}=0,0022$; $\mathrm{p}=0,0061$ dan $\mathrm{p}=0,0000 ;$ IK 95\%) (Tabel 3).

\section{Pembahasan}

Pada penelitian ini ditemukan bahwa jumlah anak laki-laki yang diperiksa pendengarannya lebih banyak bila dibandingkan dengan anak perempuan (425 laki-laki dan 277 perempuan=1,5:1), hal ini menunjukkan bahwa permasalahan gangguan dengar lebih banyak ditemukan pada anak laki-laki bila dibandingkan dengan perempuan. Kondisi yang sama juga ditemukan pada penelitian yang dilakukan Osama dkk. ${ }^{7}$ yang menunjukkan bahwa gangguan dengar lebih banyak dialami oleh anak laki-laki dibandingkan perempuan. Masa laten gelombang $\mathrm{V}$ timbul dalam waktu kurang dari 10 msec, yaitu rata-rata pada $6,07 \pm 0,39 \mathrm{msec}$ pada laki-laki dan 5,90 $\pm 0,34 \mathrm{msec}$ pada perempuan. Secara statistik masa laten absolut gelombang III, dan V juga masa laten antara gelombang IIII, III-V, dan I-V pada perempuan lebih pendek dibandingkan dengan laki-laki, sedangkan masa laten absolut gelombang I tidak berbeda antara balita laki-laki dan perempuan. Hasil yang sama didapatkan pada penelitian yang dilakukan oleh Stuart dan Yang. ${ }^{8}$ Keadaan tersebut kemungkinan terjadi oleh karena perbedaan anatomi pada jaras pendengaran perifer, volume liang telinga pada laki-laki relatif lebih luas apabila dibandingkan dengan perempuan, ${ }^{9}$ di samping itu koklea pada perempuan lebih pendek bila dibandingkan koklea laki-laki. ${ }^{10,11} \mathrm{Hal}$ tersebut dapat menyebabkan stimulus pada perempuan lebih cepat sampai, juga menyebabkan kekakuan pada membran basilaris dan dapat menyebabkan masa laten gelombang ABR timbul relatif lebih dini. ${ }^{12}$

Data yang diperoleh dari penelitian ini juga memperlihatkan tidak terdapat perbedaan yang bermakna masa laten rata-rata dan masa laten antara gelombang ABR antara telinga kanan dan kiri, baik pada balita laki-laki maupun balita perempuan pada semua kelompok usia. Hal ini menunjukkan bahwa masa laten dan masa laten antara gelombang ABR rata-rata usia 0-5 tahun penelitian ini dapat dijadikan sebagai acuan nilai normal untuk bayi dan anak dalam interval usia tersebut.

Kelompok usia 0-1 tahun memiliki masa laten absolut dan masa laten antara gelombang ABR yang lebih panjang daripada kelompok usia di atasnya, hasil ini sesuai dengan penelitian $\mathrm{Cox},{ }^{5}$ kemungkinan hal tersebut berhubungan dengan proses maturitas jaras pendengaran. Gelombang I mempunyai masa perkembangan yang paling singkat, gelombang ini mencapai masa laten yang sama dengan dewasa pada usia sekitar 2-3 bulan, sedangkan gelombang $\mathrm{V}$ mempunyai masa perkembangan yang paling lama, gelombang ini mencapai masa laten yang sama dengan dewasa pada usia sekitar dua tahun kehidupan. ${ }^{6}$

Simpulan, masa laten gelombang V pada lakilaki adalah $6,07 \pm 0,39$ msec dan pada perempuan

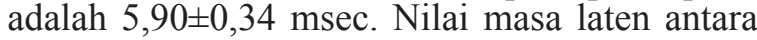
gelombang I-V pada laki-laki adalah $4,10 \pm 0,35$ msec dan pada perempuan adalah $3,95 \pm 0,31$ msec. Tidak terdapat perbedaan antara masa laten dan masa laten antara gelombang telinga kanan dan kiri baik pada laki-laki maupun perempuan pada semua kelompok usia 0-5 tahun.

Perlu dilakukan penelitian lebih lanjut untuk mengetahui apakah terdapat perbedaan gambaran morfologi gelombang ABR pada populasi usia yang lebih tua dan ras berbeda.

\section{Daftar Pustaka}

1. Yoshinaga-Itano C. Principles and guidelines for early intervention after confirmation that a child is deaf or hard of hearing. J Deaf Stud Deaf Educ. 2014;19(2):143-75.

2. Nelson H, Hygren P, Walker M, Panoscha R. Screening for speech and language delay in preschool children: systematic evidence review for the us preventive services task force. Pediatrics. 2006:e298-319.

3. Gunawan Liani Mulasari, Wijana, Yuni. Gambaran pemeriksaan OAE dan BERA pada anak dengan gangguan berbicara di Poliklinik THT-KL RSUP Dr. Hasan Sadikin Tahun 2011-2012 [skripsi]. Bandung: Universitas Padjadjaran; 2013. 
4. Hall JW, Antonelli PJ. Assessment of peripheral and central auditory function. Dalam; Jonas JT, Clark RA, penyunting. Bailey's head \& neck surgery, otolaryngology. Edisi ke-5. Baltimore: Lippincott Williams \& Wilkins. 2014. hlm. 2274-90.

5. Robert $\mathrm{B}, \mathrm{McNerney} \mathrm{K}$. Introduction to auditory evoked potentials. Dalam: Katz J, penyunting. Handbook of clinical audiology. Baltimore: Lippincott Williams \& Wilkins; 2009. hlm. 222-41.

6. Moller AR. Hearing: anatomy, physiology, and disorder of auditory system. Edisi ke-2. New York: Elsevier; 2006.

7. Osama H, Tamer S, Wael S. Prevalence and pattern of hearing loss in children in househeld National surveys in Egypt. EJENTAS. 2010;11:12-6.

8. Stuart A, Yang EY. Gender effects in auditory brainstem responses to air- and boneconducted clicks in neonates. J Commun Disord. 2001;34(3):229-39.

9. Noh H, Lee DH. Direct measurement of ear canal volume in a pediatric population: can we explain its individual variation in terms of age and body weight?. Int J Pediatr Otorhinolaryngol. 2012;76(5):658-62.

10. Miller JD. Sex differences in the length of the organ of Corti in humans. J Acoust Soc Am. 2007;121(4):151-5.

11. Abdollahi FZ, Lotfi Y. Gender difference in TEOAEs and contralateral suppression of TEOAEs in normal hearing adults. IRJ. 2011;9(14):22-5.

12. Lotfi Y, Abdollahi FZ. Age and gender effects on Auditory brainstem response (ABR). IRJ. 2012;10(16):30-6. 